\title{
REFORMA DO SISTEMA DE SAÚDE E AS NOVAS ATRIBUIÇÕES DO GESTOR ESTADUAL
}

Irineu Francisco Barreto Junior

Zilda Pereira da Silva

\begin{abstract}
Resumo: As políticas sociais brasileiras têm sido submetidas, ao longo das últimas décadas, a profundas transformações e reformas. Nesse cenário, destaca-se a criação, o processo de estruturação e de reestruturação do Sistema Único de Saúde, enfatizando as mudanças nas atribuições do gestor estadual enquanto fornecedor de serviços e administrador do sistema.

Palavras-chave: política de saúde; políticas públicas; descentralização.
\end{abstract}

\begin{abstract}
The Brazilian social politics have suffered, in the last decades, deep transformations and reforms such as the creation of the United Health System and its structuring transformations process, with emphasis on the changes of the state's management attributions as services supplier and system manager.

Key words: health politics; public politics; decentralization.
\end{abstract}

$\mathrm{N}$ este artigo, analisa-se a recente reforma das políticas sociais no Brasil e, particularmente, no Estado de São Paulo, tomando como objeto de discussão e norte analítico a descentralização das políticas de saúde, bem como a premissa de que esse processo, intensificado após a Constituição de 1988 com a criação do Sistema Único de Saúde - SUS, apontou para um aumento da responsabilidade e da participação dos municípios na gestão da saúde e, nos últimos anos, acarretou uma transformação nas atribuições e competências do gestor estadual, que adquiriu nova centralidade no sistema.

Esse gestor, especialmente a partir da implantação da Norma Operacional de Assistência à Saúde - Noas, em 2002 , teve sua responsabilidade ampliada, uma vez que a regionalização da atenção à saúde adquire espaço na agenda do SUS e ele deve ser o grande articulador e gerente do processo. É necessário diferenciar essa atuação em pelo menos duas frentes: o papel como "articulador" do sistema e como prestador de serviços de saúde.
Abordam-se, na primeira seção, aspectos teóricos e analíticos sobre o processo recente de reforma e reestruturação das políticas sociais - em especial no período que compreende a segunda metade dos anos 90 até 2002, quando findou o governo de Fernando Henrique Cardoso - para, em seguida, tratar-se dos aspectos normativos e reguladores do sistema de saúde no Brasil. Enfatizam-se, então, a Noas e as novas atribuições do gestor estadual e, por fim, a descentralização das políticas de saúde no Estado de São Paulo.

\section{APONTAMENTOS TEÓRICOS E ANALÍTICOS SOBRE O PROCESSO RECENTE DE REFORMA DAS POLÍTICAS SOCIAIS}

O processo de reestruturação do Estado e, conseqüentemente, das políticas sociais desenvolvidas ao longo da década de 90, teve no Sistema Único de Saúde um de seus casos mais emblemáticos. Concluída a transição democrática e no período que sucedeu a promulgação da Consti- 
tuição Federal de 1988, o sistema passou por uma série de rearranjos e reformas em seu modelo na procura de maior eficácia e efetividade. Por ser um sistema financiado publicamente, pelos diferentes níveis de governo União, Estados e municípios -, esteve sujeito às oscilações econômicas que afetaram o país, particularmente ao final dos anos 90, após a crise cambial de 1998.

A análise de Tapia e Henrique (1995) revela que o debate recente sobre as políticas sociais e seu reordenamento na América Latina tem sido crescentemente dominado por questões associadas à adequação do gasto e de seu financiamento às necessidades de ajuste fiscal. Isso significaria, segundo eles, um deslocamento das preocupações dominantes nos processos de democratização, em que o reordenamento das políticas sociais estava diretamente associado à participação (popular), à gestão democrática e ao ajustamento da estrutura de gasto e financiamento à geração de igualdade e proteção social com evidentes tendências universalistas.

Análise bastante crítica sobre o desenvolvimento do arranjo institucional das políticas sociais pode ser encontrada no pensamento de Behring (2003, p. 23), ao defender a hipótese de que, “durante o período em análise, o país esteve diante de uma contra-reforma do Estado, que implicou num profundo retrocesso social, em benefício de poucos". Segundo a autora, ao abandonar a perspectiva clássica do Welfare State, os Estados nacionais, incluindo o Brasil, restringem sua ação a cobrir o custo de obras de infra-estrutura sobre as quais não há interesse de investimento privado, a aplicar incentivos fiscais e garantir escoamentos suficientes e a institucionalizar o processo de liberalização e desregulamentação em nome da competitividade de suas economias.

Essa crítica é centrada nas medidas liberalizantes e desregulamentadoras da economia adotadas pelos países periféricos, na década de 90 , por orientação de organismos multilaterais como o Banco Mundial, que se tornaram conhecidas como o Consenso de Washington. Nos acordos de refinanciamento de suas dívidas e de obtenção de novos empréstimos, os países periféricos aderiram ao receituário que preconizava, entre outros aspectos, a obtenção contínua e gradualmente elevada de superávits primários em suas contas externas, para saldar os vencimentos de dívidas internas e externas e equilibrar as contas públicas. Nesse cenário, as políticas sociais caracterizam-se como gastos públicos e fazem parte do cômputo total das contas nacionais, objeto de auditoria e controle diante dos acordos firmados entre os Estados periféricos e os organismos internacionais. Para Behring (2003, p. 64), nesse cenário as políticas sociais são analisadas por um discurso meramente ideológico, que as caracteriza como paternalistas, geradoras de desequilíbrio fiscal, causadoras de custo excessivo do trabalho e que devem ser acessadas via mercado, perdendo assim, segundo a autora, sua marca de direitos sociais, conforme preconiza a Constituição Federal e todo o ideário que levou à construção, por exemplo, do Sistema Único de Saúde.

Esse posicionamento ideológico procura tirar a responsabilidade do Estado pelas políticas sociais, assim como por seu financiamento, orientando-as para a focalização e mobilização da sociedade por meio de ações individuais e voluntárias, oferecendo estímulos à procura de novos modelos de gestão, em especial de parcerias entre Estado, mercado e sociedade civil, como as organizações nãogovernamentais prestadoras de serviços de atendimento, que na área da saúde encontram seu formato nas organizações sociais.

Para Cohn (2000), em análise sobre o mesmo período, prevalece a contraposição entre política econômica e social, embate no qual se estabelece o ditame absoluto da economia sobre as formas de o país gerir a questão da pobreza e das desigualdades sociais, além de uma contradição de base entre a política de ajuste e de estabilização econômica adotada pelo governo e a possibilidade de se promover políticas sociais com impacto efetivo sobre o desenvolvimento social no país. No mesmo sentido aponta o diagnóstico proferido por Braga e Barros Silva (2001, p. 20), segundo o qual houve uma específica e perversa relação entre política econômica e política social nos anos 90 e que não seria exagero afirmar que ela é incompatível com o desenvolvimento de uma política social que assegure a qualidade de vida e que não seja comprometida pelas instabilidades, crises e desigualdades promovidas pela dinâmica econômica capitalista.

A submissão da política social à econômica geraria um cartel de ações que não combateriam efetivamente a desigualdade, uma vez que, diante das restrições orçamentárias para a intervenção pública e a oferta de serviços universais, esse cartel priorizaria e investiria de forma majoritária em políticas voltadas aos segmentos mais pobres da sociedade: a citada focalização das politicas sociais, traduzida na universalidade apenas de um conjunto básico de serviços sociais, como aqueles preconizados nos programas de Agentes Comunitários de Saúde e de Saúde da Família, gerando seletividade nos níveis mais complexos das redes de serviços. 
Segundo Cohn (2000, p. 87), reduz-se, desse modo, a questão social à da pobreza e as políticas sociais ao problema da parca disponibilidade de recursos orçamentários para o setor, arranjo no geral associado ao posicionamento ideológico anteriormente apontado por Behring (2003) e que classifica os serviços públicos estatais como perdulários, paternalistas, ineficientes e caros e não como provedores dos direitos sociais básicos e da cidadania. $O$ grande entrave que esse modelo apresenta é não enfrentar o principal problema do Brasil, que é a desigualdade, o que implicaria não apenas a adoção de políticas direcionadas ao combate à pobreza mas sim sua superação, por meio de mecanismos diretos ou indiretos de distribuição de renda.

Para Braga e Barros Silva (2001, p. 20-21), a política econômica de contenção do gasto público -, marca da década de 90 , que não apresenta perspectivas de alteração em cenário mais recente, bem como as reformas liberalizantes e desreguladoras/desregulamentadoras não deixaram espaço para uma política social vigorosa ao negarem a instituição de uma base fiscal sólida, a estabilidade de financiamento, a remuneração adequada dos serviços públicos, a manutenção de investimentos e a inovação nos aparatos públicos, deteriorando a situação social e elevando a demanda por serviços públicos. É inegável que o sistema de saúde também padece desses males, apesar do imenso avanço na construção de um arranjo institucional, regulador e norteador dessa política - desde o processo de municipalização até o esforço recente no sentido da regionalização da assistência.

Discutindo o processo de descentralização do sistema público de saúde no Brasil, Costa (2001, p. 307) aponta que essa agenda teve uma relação direta com a percepção generalizada sobre o déficit de eficiência e de responsabilização da política social, agravada pela baixa definição dos papéis para os níveis de governo que atuam no setor (União, Estados e municípios). Essa descentralização, que será discutida a seguir, teve como diretriz aumentar a eficiência, aproximando o gestor político do cidadão e criando mecanismos para o controle público e social, na definição das prioridades locais e na melhor fiscalização e controle da aplicação dos recursos municipais e daqueles recebidos mediante transferências intergovernamentais para aplicação na saúde. Essa aproximação se daria da seguinte forma: municipalização das políticas; maior controle público por meio da criação dos conselhos municipais de saúde, que devem apresentar composição paritária entre a sociedade civil e o poder público munici- pal, prestadores de serviços e trabalhadores da saúde; estabelecimento das prioridades locais no Plano Municipal de Saúde; e centralização dos recursos financeiros para financiamento da política municipal no Fundo Municipal de Saúde.

Ressalta-se que esse mecanismo de controle público foi expandido e aperfeiçoado ao longo da década de 90 com a realização das conferências municipais de saúde e a criação dos conselhos locais ou gestores de unidades de saúde.

O gestor estadual foi aquele que sofreu o maior impacto no processo de descentralização ao ter seu papel original de executor de ações e de contratante de serviços privados e filantrópicos substituído por uma função de coordenação, apoio e regulamentação do sistema estadual de saúde (COSTA, 2001, p. 318).

O Banco Mundial, conforme aquele autor, sugere um conjunto de ações para o gestor estadual a fim de aprimorar e fortalecer suas funções de articulador regional de políticas. São elas:

- desenvolver um modelo eqüitativo de distribuição de recursos entre municipalidades ajustando os modelos de distribuição per capita e o baseado na produção de serviços;

- fortalecer a utilização compartilhada de serviços e especializações de referência entre municípios para promover a economia de escala e estimular as oportunidades de especialização municipal, entre os quais os consórcios intermunicipais;

- estimular a definição de prioridades nas intervenções de saúde;

- estabelecer combinação de preços, orçamento global e outros instrumentos para a definição de prioridades pelos gestores locais, considerando que as transferências intergovernamentais tendem a ser de um a outro fundo;

- estudar a ineficiência alocativa em decorrência da ausência de estratégias de tratamento preventivo;

- planejar os investimentos futuros em incorporação tecnológica e equipamentos de acordo com as novas funções na gestão de custos dos governos federal e estadual;

- estimular que as organizações e serviços públicos sejam mais autônomos e responsáveis, introduzindo mecanismos de flexibilidade nas relações de trabalho, contratos de gestão e competição para a prestação de serviços específicos demandados pelo gestor (Costa, 2001, p. 318-319).

Costa (2001), ao analisar o processo de descentralização setorial, conclui que são poucas as evidências que ela 
tenha afetado de modo negativo a qualidade dos serviços, que a municipalização tenha causado negligência de mecanismos de responsabilização dos governos locais ou mesmo que ela possa ter produzido uma crise de legitimidade do sistema público de saúde. O processo, na verdade, teria: projetado as secretarias municipais de saúde na esfera dos governos municipais; ampliado a capacidade de gestão em razão das novas responsabilidades; aumentado a força de trabalho em saúde, a oferta de serviços ambulatoriais e as ações de saúde coletiva; e induzido a maior comprometimento de recursos do orçamento municipal com o setor saúde.

A seguir, discute-se a trajetória recente da descentralização da política de saúde no Brasil, seus principais marcos normativos e regulatórios e as mudanças de atribuições dos gestores públicos, particularmente o estadual.

\section{ASPECTOS NORMATIVOS E REGULADORES DO SISTEMA DE SAÚDE NO BRASIL}

A descentralização da política da saúde constituiu-se numa peça central da agenda reformista brasileira ao longo da década de 80 e seguintes porque a centralização característica do autoritarismo burocrático do regime militar pós1964 converteu a descentralização, por um lado, num princípio ordenador das mudanças para os setores de esquerda e, por outro, em uma peça também importante para o pensamento liberal de oposição ao regime (MELO, 1996).

Nesse cenário, iniciou-se, no Estado de São Paulo, o processo de descentralização no setor de saúde, que passou por uma série de desdobramentos, como o desenvolvimento das Ações Integradas de Saúde - AIS e o surgimento do Movimento da Reforma Sanitária, que por sua vez desempenharia papel decisivo nas negociações que criaram o Sistema Único de Saúde - SUS, na Assembléia Nacional Constituinte. Entre os diversos capítulos da Constituição Federal, um deles determinou as linhas gerais do que viria a se configurar no novo sistema de saúde brasileiro. Draibe (1997) descreve sua configuração, quando afirma que a Constituição de 1988 redefine o conceito de Seguridade Social, incluindo previdência, saúde e assistência social e tendo como princípios e objetivos: a universalidade da cobertura e do atendimento; a uniformidade e equivalência dos benefícios e serviços a toda a população; a seletividade e distributividade na prestação dos benefícios e serviços; a irredutibilidade do valor dos benefícios; a eqüidade na forma de participação do custeio; a diversidade da base de financiamento; a democra- tização e descentralização da gestão, com participação da comunidade.

É fundamental, ainda para Draibe (1997), que, em relação à saúde, o princípio da universalização da cobertura e do atendimento seja o mais diferenciado do sistema anterior, garantindo o acesso igualitário a toda a população, o que deveria ser afirmado também pelas futuras proposições em termos organizacionais - a definição de uma rede integrada, descentralizada, regionalizada e hierarquizada.

As negociações e os conflitos para a consolidação da nova política não se encerraram com a nova Constituição. Além da criação do SUS e de suas diretrizes, era necessário regulamentá-lo e torná-lo realidade. O processo de regulamentação do sistema de saúde obtém significativo avanço com a promulgação da Lei Orgânica de Saúde, Lei n. 8.080, de setembro de 1990, que define o SUS como um conjunto de ações e serviços de saúde prestados por órgãos e instituições públicas de todos os níveis de governo - com caráter complementar para a iniciativa privada; determina a atuação permanente na análise das condições de saúde e seus determinantes; atribui a responsabilidade pela formulação das políticas de saúde e pela assistência às pessoas; determina seus princípios e diretrizes, ressaltandose, entre outros, universalidade de acesso, integralidade da assistência, eqüidade, participação da comunidade, descentralização político-administrativa, com direção única em cada esfera de governo e articulação dos recursos financeiros, tecnologia, material e recursos humanos de todos os níveis.

Essa lei definiu, também, as atribuições e competências de cada nível de governo. Aos municípios, coube o gerenciamento e execução dos serviços públicos de saúde, criando os sistemas locais. Aos Estados, coube promover a descentralização dos serviços e ações de saúde, prestando apoio técnico e financeiro aos municípios. Apenas supletivamente os Estados executarão ações e serviços de saúde. Suas atribuições referem-se, principalmente, ao acompanhamento, ao controle e à avaliação das redes hierarquizadas do SUS, bem como à gestão dos sistemas públicos de alta complexidade, de referência regional e estadual.

Em dezembro de 1990 foi sancionada a Lei n. 8.142, que dispõe sobre a participação da comunidade na gestão do SUS e sobre as transferências intragovernamentais de recursos financeiros na área da saúde. Durante o governo de Fernando Collor de Mello (1990-92), porém, ocorreu uma paralisação no processo de descentralização das políticas de saúde. Nesse período, foram alteradas as relações entre as diferentes esferas de governo definidas no 
SUS, estabelecendo o pagamento pela produção dos serviços públicos de saúde. Essa alteração transformou os prestadores públicos - Estados e municípios - em meros vendedores de serviços para a União. O que estava previsto para ser uma parceria transformou-se numa relação de compra e venda, configurando um movimento de recentralização, segundo Junqueira (1997).

A Norma Operacional Básica - NOB SUS 93, editada na gestão de Jamil Haddad no Ministério da Saúde, no governo de Itamar Franco, procurou desmontar a lógica então prevalecente na relação entre União, Estados e municípios, que contradizia os princípios do SUS. Procurouse, por meio da NOB, disciplinar a construção do Sistema Único de Saúde. Sem desmontar o pagamento por produção - disfunção herdada do governo Collor, mas que contava com apoio dos municípios por permitir o repasse dos recursos diretamente de Brasília, sem a intermediação dos governos estaduais -, foi instituída uma nova forma de relação, retomando a descentralização. Essa norma é o referencial de implantação do SUS desde aquele momento, sistematizando a gestão do sistema e dos serviços, num esquema de transição com diferentes níveis de responsabilidade de estados e municípios e, por relação, do próprio nível federal. Arretche (1996) afirma que a NOB-93 fortalece a relação entre governo federal e municípios e supõe graus distintos de responsabilidade sobre a gestão dos serviços. A norma estabeleceu que a habilitação somente pode ocorrer por solicitação municipal, a qual pode se dar mediante três formas de adesão: a gestão incipiente; a gestão parcial; e a gestão semiplena dos serviços.

Cumpridos os requisitos básicos e aprovada a adesão ao processo de municipalização das políticas de saúde, as cidades passam a ter inúmeras atribuições na gestão do sistema local de saúde, que diferem de acordo com o modelo selecionado.

A partir de janeiro de 1998, o sistema de saúde brasileiro foi submetido a uma profunda reestruturação, com a entrada em vigor de uma nova regulamentação, a Norma Operacional Básica do Sistema Único de Saúde - 1996, a NOB-96. ${ }^{1}$ Esta foi editada na gestão de Carlos César Albuquerque à frente do Ministério da Saúde, mas as negociações acerca de seu conteúdo e forma tiveram início durante a gestão do ministro Adib Jatene, ambas no primeiro governo de Fernando Henrique Cardoso. A NOB-96 inicia-se com o dístico "Gestão plena com responsabilidade pela saúde do cidadão" e com a citação dos marcos legais que a norteiam, ou seja, os princípios e diretrizes consubstanciados na Constituição Federal e nas Leis $\mathrm{n}^{\text {os }} 8.080 / 90$ e $8.142 / 90$. Com isso, reafirmam-se, ao menos formalmente, os princípios da universalidade, da eqüidade, da integralidade da assistência e da responsabilização do Estado pela saúde dos cidadãos.

Apesar da importância da reafirmação desses princípios, a mais significativa diretriz da NOB-96 consiste no radical avanço na responsabilidade dos municípios pela gestão da política de saúde:

A presente NOB tem por finalidade promover e consolidar o pleno exercício, por parte do poder público municipal e do Distrito Federal, da função de gestor de atenção à saúde de seus munícipes, com a conseqüente redefinição das responsabilidades dos Estados, do Distrito Federal e da União, avançando na consolidação dos principios do SUS. Esse exercício compreende, portanto, não só a responsabilidade por algum tipo de prestação de serviços de saúde, como, da mesma forma, a responsabilidade pela gestão de um sistema que atenda, com integralidade, a demanda das pessoas pela assistência à saúde e às exigências sanitárias ambientais. Busca-se, dessa forma, a plena responsabilidade do poder público municipal (MINISTÉRIO DA SAÚDE, 1997).

Redefinindo também o papel dos Estados e da União na gestão do sistema, a NOB-96 determina que estes são sempre co-responsáveis pelo SUS em suas respectivas competências ou na ausência da função municipal.

A NOB-96 avança mais ainda na responsabilização dos municípios pela gestão da política de saúde com a criação do SUS municipal, que consiste em subsistemas, um para cada município, que devem responder pela totalidade das ações e de serviços de atenção à saúde no âmbito do SUS. O SUS municipal responde ainda pela relação entre o SUS e os estabelecimentos prestadores de serviços - sejam estatais, sejam privados - e sua gerência é, necessariamente, da competência do poder público e exclusiva da esfera municipal de governo. Com a criação do SUS municipal e o conseqüente aumento da responsabilização dos municípios quanto à gestão da política de saúde, fez-se necessária a redefinição das atribuições dos Estados e da União na gestão do SUS. Quatro atribuições básicas - não exclusivas ou seqüenciais - foram direcionadas aos Estados:

- exercer a gestão do SUS no âmbito estadual;

- promover as condições e incentivar o poder municipal para que assuma a gestão da atenção à saúde de seus munícipes, sempre na perspectiva da atenção integral; 
- assumir em caráter transitório a gestão da atenção à saúde das populações pertencentes a municípios que ainda não tomaram para si essa responsabilidade;

- ser o promotor da harmonização, da integração e da modernização dos sistemas municipais, compondo assim o SUS estadual (MINISTÉRIO DA SAÚDE, 1997).

Dentre as mudanças definidas pelo Ministério da Saúde por meio da edição da NOB-96, destaca-se a alteração nos modelos de gestão municipal da saúde. Essa nova normatização extingue os três modelos então vigentes e cria duas novas categorias distintas de gestão às quais os municípios podem se habilitar. Os modelos diferenciamse diante das responsabilidades que serão atribuídas ao gestor municipal, dos requisitos necessários para sua aprovação e das prerrogativas relativas a cada uma dessas modalidades. Os dois novos modelos são: Gestão Plena da Atenção Básica e Gestão Plena do Sistema Municipal. O modelo da Gestão Plena do Sistema Municipal é mais complexo e exige maior capacidade do município em gerilo do que o modelo da Gestão Plena da Atenção Básica, mas, nos dois formatos, transfere-se uma significativa parcela da responsabilidade pelas condições de saúde das populações para os municípios.

Além de redefinir a inserção no Sistema Único de Saúde, a NOB-96 redefine os mecanismos de financiamento de ações e serviços de saúde até então vigentes, na tentativa de reverter a lógica anterior, fundada na compra e venda de serviços entre a União e os demais prestadores do SUS, enquadrando-se nessa categoria, até então, os municípios. Nos moldes da NOB-93, revogada com a edição da NOB-96, apenas os municípios habilitados na gestão semiplena recebiam recursos via transferência regular e automática - fundo a fundo - e eram os únicos a possuírem maior autonomia na gestão do sistema local de saúde. A NOB-96 objetiva reverter essa lógica, aumentando a participação na transferência entre fundos dos recursos federais a Estados e municípios e reduzindo a transferência por remuneração por serviços produzidos. O financiamento do SUS continua de responsabilidade das três esferas de governo e cada uma delas deve assegurar o aporte regular de recursos ao respectivo Fundo de Saúde.

No novo sistema de transferência de recursos passam a existir o Incentivo ao Programa de Saúde da Família PSF e o Incentivo ao Programa e Agentes Comunitários de Saúde - PACS. O Programa de Saúde da Família consiste na criação de equipes de saúde em regime de dedicação exclusiva e que vivam no mesmo local em que exer- cerão a atenção a uma comunidade entre 800 e 1.000 famílias, priorizando as ações de proteção e promoção à saúde dos indivíduos e da família de forma integral e contínua (MINISTÉRIO DA SAÚDE, 1994). O Programa de Agentes Comunitários da Saúde objetiva - mediante ação de lideranças locais, contratadas e capacitadas para atuarem como agentes visitadores na sua região - melhorar a capacidade da população de cuidar da sua saúde individual e da saúde de sua comunidade, transmitindo-lhe informações e conhecimentos (MINISTÉRIO DA SAÚDE, 1994).

O PSF significa reorientação na política de saúde, permitindo que as ações focalizem adequadamente os problemas, ampliando o acesso da população aos serviços de saúde e aumentando a cobertura assistencial, em especial em áreas de baixa renda, nas quais a oferta é mais escassa. O PACS é considerado, nessa proposta de governo, um componente da estratégia de saúde da família.

\section{A NOAS E AS NOVAS ATRIBUIÇÕES DO GESTOR ESTADUAL}

Diante do exposto, verifica-se que a regulação do sistema de saúde brasileiro entre a promulgação da Constituição Federal, em 1988, e até o final da década de 90, em que vigoraram as NOBs 93 e 96, foi fortemente orientada para a descentralização da política pela municipalização das ações e dos serviços de saúde. Exitosa em princípio, a municipalização passou a apresentar limites e restrições ao final da década, em especial no que se refere à organização da atenção dos serviços regionais, de referência intermunicipal e de alta complexidade. Para reorganizar a atenção regional em sistemas de saúde não necessariamente confinados aos territórios municipais e, portanto, sob responsabilidade coordenadora dos governos estaduais, o Ministério da Saúde, após cerca de um ano de debates que envolveram ainda as representações dos secretários estaduais e municipais de saúde e o Conselho Nacional de Saúde, editou, a princípio em 2001 e, numa edição aperfeiçoada, em 2002, a Norma Operacional de Assistência à Saúde - Noas SUS 01/2002. Seus principais objetivos foram ampliar a responsabilidade dos municípios na atenção básica; estabelecer a regionalização como estratégia de hierarquização dos serviços de saúde e de busca de maior eqüidade; criar mecanismos para o fortalecimento da capacidade de gestão do SUS e atualizar critérios de habilitação dos Estados e municípios. 
Dentre os principais aspectos e inovações advindos da implantação Noas, destaca-se a diretriz de regionalização dos sistemas como estratégia de hierarquização dos serviços de saúde e de busca de maior eqüidade, com a elaboração do Plano Diretor de Regionalização - PDR, que se fundamenta na conformação de sistemas funcionais e resolutivos de assistência à saúde, por meio da organização dos territórios estaduais em regiões/microrregiões e módulos assistenciais; da conformação de redes hierarquizadas de serviços; do estabelecimento de mecanismos e fluxos de referência e contra-referência intermunicipais, com o objetivo de garantir a integralidade da assistência e o acesso da população aos serviços e ações de saúde de acordo com suas necessidades (MINISTÉRIO DA SAÚDE, 2002).

Considerando a regionalização como novo princípio e diretriz da descentralização da saúde, a expectativa é de transformações em um contexto que anteriormente apontava para a municipalização e para o fortalecimento de uma perspectiva regional e intermunicipal para a assistência à saúde. Nessa nova perspectiva, as secretarias estaduais de saúde adquirem papel central no estabelecimento de novos pactos intermunicipais e na distribuição dos recursos financeiros, uma vez que a antiga formulação de transferências baseadas em valores per capita e por produção considerará também os municípios que são pólos de atendimento regional e que oferecem equipamentos para realização de procedimentos de alto custo ou complexidade. Caberá aos Estados, de acordo com a Programação Pactuada e Integrada - PPI e dentro do limite financeiro estadual, prever a parcela dos recursos a serem gastos em cada município para cada área de alta complexidade, destacando a quantidade a ser utilizada com a população do próprio município e aquela a ser gasta com a população de referência.

Ainda segundo a Noas, os municípios que tiverem em seu território serviços de alta complexidade ou custo elevado, quando habilitados em Gestão Plena do Sistema Municipal, deverão desempenhar as funções referentes à organização dos serviços de alta complexidade em seu território, para assegurar o comando único sobre os prestadores. A programação da Atenção de Alta Complexidade deverá ser precedida de estudos da distribuição regional de serviços e da proposição pela Secretaria Estadual de Saúde - SES de um limite financeiro claro para seu custeio. O Plano Diretor de Regionalização apontará as áreas de abrangência dos municípios-pólo e dos serviços de referência na Atenção de Alta Complexidade.
Nessa nova ênfase atribuída à regionalização e ao papel do gestor estadual, destaca-se que caberá a ele a coordenação da Programação Pactuada e Integrada no âmbito do Estado, por meio do estabelecimento de processos e métodos que assegurem, dentre outras, a operacionalização do Plano Diretor de Regionalização e de estratégias de regulação do sistema, mediante a adequação de critérios e instrumentos de alocação e pactuação dos recursos assistenciais e a adoção de mecanismos que visem regular a oferta e a demanda de serviços, organizar os fluxos e garantir o acesso às referências. A PPI, aprovada pela Comissão Intergestores Bipartite, deverá nortear a alocação de recursos federais da assistência entre municípios pelo gestor estadual, resultando na definição de limites financeiros para todos os municípios do Estado, independentemente da sua condição de habilitação.

A garantia de acesso da população aos serviços não disponíveis em seu município de residência é de responsabilidade do gestor estadual, de forma solidária com os municípios de referência, observados os limites financeiros, e ele deverá organizar o sistema de referência, utilizando mecanismos e instrumentos necessários, compatíveis com a condição de gestão do município onde os serviços estiverem localizados.

\section{DESCENTRALIZAÇÃO DAS POLÍTICAS DE SAÚdE NO ESTADO DE SÃO PAULO}

A municipalização dos serviços de saúde estaduais começou, em 1987, com a transferência de Unidades Básicas de Saúde - UBS e de laboratórios locais no interior do Estado; concomitantemente, a Secretaria Estadual começou a assumir os serviços hospitalares e ambulatoriais do antigo Instituto Nacional de Assistência Médica da Previdência Social - Inamps. Essa etapa foi concluída em 2002, com todas as unidades de atenção primária transferidas para a gestão dos municípios. Fato que ocorreu apenas nesse ano em razão da adesão tardia do município de São Paulo ao processo de descentralização, em decorrência da opção da prefeitura paulistana pela adoção do modelo cooperativado do Plano de Assistência à Saúde - PAS, entre 1996 e 2001.

A reforma do sistema de saúde brasileiro, que culminou com a implantação do SUS, em 1988, garantiu uma expressiva ampliação da rede de serviços no âmbito do setor público. Em 1986, no Estado, havia 2.157 estabelecimentos públicos de saúde, número que praticamente dobrou em 2002, atingindo mais de 4 mil unidades. Esse movimento 
se deu particularmente na rede municipal, espelhando um dos pilares do SUS, que é a diretriz de descentralização dos serviços, com transferência de unidades para a esfera municipal, especialmente da rede ambulatorial. As esferas federal e estadual apresentaram diminuição importante no número de unidades sem internação sob sua gerência, no período 1986-2002, enquanto a rede municipal passou de 969 para 3.738 estabelecimentos, o que significa que as prefeituras assumiram o gerenciamento de cerca de $96 \%$ das unidades públicas em 2002 (Tabela 1). dora para assegurar a organização de redes assistenciais regionalizadas, hierarquizadas.

Como citado anteriormente, a Noas vem em resposta a essa preocupação, centrada na questão da regionalização e com revalorização do papel do gestor estadual.

Como os municípios devem garantir o primeiro nível de atenção à saúde dos cidadãos e garantir a universalidade de acesso ao SUS, cabe ao gestor estadual o papel de avaliar e acompanhar essas atividades, visando a melhoria da qualidade e resolubilidade da assistência primária desen-

TABELA 1

Estabelecimentos de Saúde, por Regime de Atendimento, segundo Esfera Administrativa Estado de São Paulo - 1986-2002

\begin{tabular}{|c|c|c|c|c|c|c|c|c|c|}
\hline \multirow{2}{*}{ Esfera Administrativa } & \multicolumn{3}{|c|}{ Com Internação } & \multicolumn{3}{|c|}{ Sem Internação } & \multicolumn{3}{|c|}{ Total } \\
\hline & 1986 & 1992 & 2002 & 1986 & 1992 & 2002 & 1986 & 1992 & 2002 \\
\hline Total & 96 & 179 & 186 & 2.061 & 3.081 & 3.907 & 2.157 & 3.260 & 4.093 \\
\hline Federal & 11 & 8 & 5 & 112 & 38 & 12 & 123 & 46 & 17 \\
\hline Estadual & 51 & 65 & 62 & 980 & 519 & 157 & 1.031 & 584 & 219 \\
\hline Municipal & 34 & 106 & 119 & 969 & 2.524 & 3.738 & 1.003 & 2.630 & 3.857 \\
\hline
\end{tabular}

Fonte: IBGE. Pesquisa de Assistência Médico-Sanitária - AMS.

$\mathrm{Na}$ rede hospitalar, os movimentos mais importantes foram a transferência dos hospitais do Inamps para o governo estadual, no começo da década de $90,{ }^{2}$ e a ampliação dos serviços municipais, que evoluíram de 34 unidades com internação, em 1986, para 119 em 2002. Apesar de a rede municipal de estabelecimentos com internação ser maior do que a estadual, é importante ressaltar que a maioria das unidades municipais é de pequeno e médio portes, incluindo as unidades mistas de saúde, enquanto a rede estadual reúne hospitais maiores e de nível terciário.

No balanço dos avanços e limitações da descentralização, a questão da regionalização passa a se destacar no debate setorial, no final dos anos 90 , como possibilidade de promover a descentralização com eqüidade no acesso aos serviços. Segundo Souza (2001, p. 453)

os grandes avanços no âmbito da descentralização político-administrativa, com fortalecimento dos gestores locais e as mudanças na organização da atenção básica induzidas pela NOB SUS 01/96, evidenciam a necessidade de maior articulação entre os sistemas municipais e de fortalecimento das secretarias estaduais de saúde na sua função regula- volvida pela esfera municipal (BARATA et al., 2003). No Estado de São Paulo, praticamente toda a atenção básica está sob gestão municipal, o que inclui ações de vacinação, consultas médicas básicas como de pediatria, ginecologia e pré-natal, controle de hipertensão e diabetes, ações coletivas de saúde bucal, etc. (Tabela 2).

A integralidade da assistência deve ser garantida, além da atenção básica, pelos serviços de atenção secundária e terciária, desenvolvida em ambulatórios de especialidades e em hospitais gerais e especializados, incluídos os universitários. Nesses níveis de atenção são realizados procedimentos de média e alta complexidade, tais como: exames especializados (ultra-sonografia, mamografia, ressonância magnética), consultas especializadas (ortopedia, neurologia, etc.), cirurgias das mais simples aos transplantes. Na gestão municipal de atenção básica, os serviços hospitalares e os ambulatórios de especialidades ficam sob administração direta do gestor estadual e em alguns casos, sob sua gerência, independentemente de serem serviços de referência regional ou local, enquanto na gestão plena do sistema municipal apenas os serviços terciários e especializados mais complexos ficam na gestão estadual. 
TABELA 2

Procedimentos Ambulatoriais, por Tipo de Gestão, segundo Grupos de Procedimentos

Estado de São Paulo - 2003

\begin{tabular}{|c|c|c|c|c|c|c|}
\hline \multirow{2}{*}{ Grupos de Procedimentos } & \multicolumn{2}{|c|}{ Gestão Municipal } & \multicolumn{2}{|c|}{ Gestão Estadual } & \multicolumn{2}{|c|}{ Total } \\
\hline & $\mathrm{N}^{\text {os }}$ Absolutos & $\%$ & $\mathrm{~N}^{\text {os }}$ Absolutos & $\%$ & $\mathrm{~N}^{\text {os }}$ Absolutos & $\%$ \\
\hline Total & 344.890 .334 & 67,47 & 166.278 .203 & 32,53 & 511.168 .537 & 100,00 \\
\hline Atenção Básica & 255.270 .899 & 99,99 & 13.684 & 0,01 & 255.284 .583 & 100,00 \\
\hline Especializados & 85.749 .147 & 44,71 & 106.038 .658 & 55,29 & 191.787 .805 & 100,00 \\
\hline Assistenciais de Alta Complexidade (1) & 3.485 .404 & 30,31 & 8.015 .589 & 69,69 & 11.500 .993 & 100,00 \\
\hline
\end{tabular}

Fonte: Ministério da Saúde/Secretaria de Assistência à Saúde - SAS. Sistema de Informações Ambulatoriais do SUS - SIA/SUS.

(1) Exclui medicamentos

Em 2003, no Estado de São Paulo, 55\% dos procedimentos especializados realizados em ambulatórios estavam sob gestão estadual e $45 \%$ sob gestão municipal, sendo a quase totalidade em municípios habilitados na Gestão Plena do Sistema Municipal. Os procedimentos assistenciais de alta complexidade estão também em maior parte sob a gestão estadual $(70 \%)$, entre os quais destacam-se alguns serviços em que a concentração na rede estadual é maior como hemoterapia $(81 \%)$, ressonância magnética $(86 \%)$ e radiologia intervencionista $(88 \%)$.

A distribuição dos recursos de maior complexidade pelo território paulista é historicamente desigual. Na rede hospitalar, por exemplo, observa-se que $70 \%$ dos leitos de hospitais universitários localizam-se nas regiões metropolitanas de São Paulo e de Campinas (FUNDAÇÃO SEADE, 2004). Na rede ambulatorial, destaca-se, por exemplo, que os exames de ressonância magnética realizados no SUS, em 2003, no Estado, ocorreram em apenas 21 municípios; $57 \%$ do total foi realizado no município de São Paulo. Assim, observa-se que o gestor estadual tem importante papel na busca pela garantia de eqüidade entre os municípios, no acesso aos serviços de maior complexidade, de forma a garantir a integralidade na atenção à saúde para todos os usuários do SUS no Estado (BARATA et al., 2003). Nesse contexto, assume relevância o papel da Secretaria Estadual de coordenação do processo de planejamento regional e de desenvolvimento de mecanismos de regulação tanto para a assistência hospitalar e ambulatorial como para o atendimento de urgência/emergência.

\section{CONSIDERAÇÕES FINAIS}

O Sistema Único de Saúde pode ser considerado o mais emblemático caso de reforma das políticas sociais no Bra- sil nos anos recentes. Desde a segunda metade da década de 80 , quando de sua criação, o sistema foi submetido a uma série de rearranjos institucionais que procuraram efetivá-lo, tornando-o realidade e não apenas um projeto e, ao mesmo tempo, solucionando os conflitos e entraves inerentes à distribuição de competências entre os gestores federal, estadual e municipal. Esse desenvolvimento fez parte do grande processo de reforma das políticas sociais estabelecido pelo governo brasileiro e, dessa maneira, esteve submetido às crises que o Estado atravessou nesse período, em especial as crises financeiras e fiscais que em diversos momentos atrasaram a marcha das reformas e impediram que elas tivessem resultados mais efetivos no combate às desigualdades econômicas e sociais que marcam o país.

Diante dos entraves advindos da municipalização das políticas de saúde, foi possível verificar que a regionalização da atenção conquistou espaço na agenda do SUS e que para articular o sistema regionalizado o gestor estadual, através das secretarias estaduais de saúde, adquiriu papel central na gestão do sistema. No Estado de São Paulo, em particular, o gestor estadual praticamente deixou de atuar na atenção básica. No entanto, ainda é responsável por parcela significativa da oferta de procedimentos especializados e de alta complexidade, principalmente em estabelecimentos universitários. A principal atribuição do gestor estadual paulista, no novo desenho do sistema de saúde, é articular os sistemas municipais e organizar as redes assistenciais regionalizadas, estabelecendo como principal objetivo combater as desigualdades regionais e intermunicipais, para que a oferta de serviços seja distribuída de maneira mais equânime entre a população do Estado. 


\section{NOTAS}

1. A Norma Operacional Básica SUS 01/96 foi editada em janeiro de 1997 e passou a vigorar em janeiro de 1998.

2. As unidades que, em 2002, continuam com a gerência do governo federal referem-se a hospitais universitários e aqueles ligados às forças armadas, que atendem clientela fechada.

\section{REFERÊNCIAS BIBLIOGRÁFICAS}

ARRETCHE, M.T.S. Mitos da descentralização: mais democracia e eficiência nas políticas públicas? Revista Brasileira de Ciências Sociais, São Paulo: Anpocs, ano 11, n. 31, 1996.

BARATA, L.R.B.; TANAKA, O.Y.; MENDES, J.D.V. O papel do gestor estadual no Sistema Único de Saúde - SUS. São Paulo, jun. 2003. Mimeografado. Disponível em:

$<$ http://www.saude.sp.gov.br>. Acesso em: 28 mar. 2004.

BEHRING, E.R. Brasil em contra-reforma: desestruturação do Estado e perda de direitos. São Paulo: Cortez, 2003.

BRAGA, J.C. de S.; BARROS SILVA, P.L. A mercantilização admissível e as políticas públicas inadiáveis: estrutura e dinâmica do setor saúde no Brasil. In: NEGRI, B.; GIOVANNI, G. Brasil: radiografia da saúde. Campinas: Unicamp, 2001.

COHN, A. As políticas sociais no governo FHC. Tempo Social, São Paulo, USP, v. 11, n. 2, 2000.

COSTA, N.R. A descentralização do sistema público de saúde no Brasil: balanço e perspectiva. In: NEGRI, B.; GIOVANNI, G. Brasil: radiografia da saúde. Campinas: Unicamp, 2001.
DRAIBE, S.M. A política social na América Latina: o que ensinam as experiências recentes de reforma. In: DINIZ, E.; AZEVEDO, S. (Org.). Reforma do Estado e democracia no Brasil. Brasília: Editora UNB/Enap, 1997.

FUNDAÇÃO SEADE. Anuário Estatístico do Estado de São Paulo 2002. São Paulo, 2004. Disponível em: <http://www.seade.gov.br $>$. Acesso em: 07 maio 2004.

JUNQUEIRA, L.A.P. Descentralização e mudanças nas organizações públicas de saúde. Cadernos Fundap - Desafios da Gestão Pública Paulista, São Paulo, Fundap, n. 21, 1997.

MELO, M.A. Crise federativa, guerra fiscal e hobbesianismo municipal: efeitos perversos da descentralização? São Paulo em Perspectiva, São Paulo, Fundação Seade, v. 10, n. 3, jul./set. 1996.

MINISTÉRIO DA SAÚDE. Norma Operacional de Assistência à Saúde - NOAS SUS 01/2002. Brasília, DF: 2002.

. Norma Operacional Básica do Sistema Único de SaúdeNOB SUS 1996. Brasília, DF: jan. 1997.

. Programa de Agentes Comunitários de Saúde. Brasília, DF: Ministério da Saúde/Fundação Nacional da Saúde, 1994.

SOUZA, R.R. A regionalização no contexto atual das políticas de saúde. Ciência \& Saúde Coletiva, v. 6, n. 2, p. 451-555, 2001.

TAPIA, J.R.B.; HENRIQUE, W. Crise, reforma e políticas sociais na América Latina. São Paulo em Perspectiva, São Paulo, Fundação Seade, v. 9, n. 4, out./dez. 1995.

Irineu Francisco Barreto Junior: Sociólogo, Doutor em Ciências Sociais e Analista da Fundação Seade.

Zilda Pereira da Silva: Socióloga, Mestra em Saúde Pública e Analista da Fundação Seade. 